\title{
Introducing 'productive interactions' in social impact assessment
}

\author{
Jack Spaapen and Leonie van Drooge
}

\begin{abstract}
Social impact of research is difficult to measure. Attribution problems arise because of the often long time-lag between research and a particular impact, and because impacts are the consequences of multiple causes. Furthermore, there is a lack of robust measuring instruments. We aim to overcome these problems through a different approach to evaluation where learning is the prime concern instead of judging. We focus on what goes on between researchers and other actors, and so narrow the gap between research and impact, or at least make it transparent. And by making the process visible, we are able to suggest indicator categories that arguably lead to more robust measuring instruments. We propose three categories of what we refer to as 'productive interactions': direct or personal interactions; indirect interactions through texts or artefacts; and financial interactions through money or 'in kind' contributions.
\end{abstract}

$\mathrm{T}$ THE ASSESSMENT of social impact of research is difficult compared to the assessment of scientific impact. For the assessment of scientific impact, broadly accepted indicators exist such as citation scores or the H-index. For social impact assessment, reliable and accepted indicators are not available. Yet, against the background of increasing global competition and the need for stronger links between the knowledge sector and industry and society, politicians and policy-makers at all levels are calling for robust methods of social impact assessment.

There are a number of well-known problems confronting the practice of social impact assessment (European Commission, 2005). First, there is no dataset comparable to the Web of Science that can be used to identify societal output or communication of

\footnotetext{
Jack Spaapen is policy advisor and executive secretary of the Humanities Research Council at the Royal Netherlands Academy of Arts and Sciences, PO Box 19121, 1000 GC Amsterdam, The Netherlands; Email: jack.spaapen@bureau.knaw.nl; Tel: +31 20 5510762. Leonie van Drooge is researcher at the Department of Science System Assessment, Rathenau Institute, PO Box 95366, 2509 CJ Den Haag, The Netherlands; Email: l.vandrooge@rathenau.nl; Tel: +31 703421542.

The research leading to these results has received funding from the European Union Seventh Framework Programme (FP7/2007-2013) under grant agreement No. 230330.
}

research. Quantitative data are hardly available, monitoring of data is practically non-existent and there is a lack of consensus about what data to gather. Second, social impact is often geared towards a variety of audiences, each having their own interests in and expectations of research. Third, it is difficult to link a particular social impact to a specific research effort. This has two causes: the attribution of observed impacts specifically to research activities; and the issue of temporality, that is, the time span between research and its embodiment in products, processes or social practices.

Cozzens and Snoek (2010) conclude in their extensive review of the literature that there is an écart or gap between the practice of evaluation and the majority of the research literature. The evaluation practice is primarily directed towards identifying social impact using linear concepts or models, whereas most of the literature discusses the process of how impact is achieved using network and interaction concepts. To narrow that gap, one has to concentrate on what actually happens in the process of knowledge production, and on the role different stakeholders play in this process. This will inevitably lead to reconsidering current evaluation practices. The introduction of knowledge about the process into assessment procedures will also help us to understand how (potential) social impact is being achieved. 
This focus on the interaction process brings new elements into the evaluation: different questions and different people. For example, what roles do different stakeholders play in the process of achieving impact, and who will be included in evaluation teams? One way or another, relevant stakeholders have to be involved in evaluation procedures, be it as member of review committees or through forms of consultancy.

Examples of practices where stakeholders are included in one or more stages of evaluation can be found in sectors like development interventions (Vaessen, 2010) and education. In the late 1980s, Guba and Lincoln (1989) introduced stakeholderoriented evaluation in the educational sector. As we have described elsewhere (Spaapen et al, 2007: 54$55)$, they claim that evaluation practice in the field of education has developed from measuring the performance of individual teachers to the effectiveness of programs and then to a much more comprehensive form that they refer to as fourth-generation evaluation. Such evaluation is organized by the claims, concerns and issues of various interested parties ('stakeholding audiences'), and uses social constructivist methods. This means that the evaluation method includes all relevant stakeholders, elicits from the stakeholders their main interests in the evaluation, and builds an evaluation context through which these different constructions can be understood and critiques can be taken into account.

Looking at research evaluation in this more comprehensive way also connects to the approach Nowotny et al (2001) have chosen to analyse the integration of science and society, in particular the concept of socially robust knowledge. Against the background of what the authors call the co-evolution of science and society, innovation in society is no longer regarded as predominantly shaped by scientific and technological progress, but as the result of an iterative process of interaction between scientific and other social domains, technical experts, professional organizations, industry, government and the public at large (Smits and Kuhlmann, 2004).

Furthermore, it appears that $75 \%$ of successful innovation depends on social innovation, such as new forms of organizing work and relations, and only $25 \%$ on R\&D and new knowledge (Volberda et al, 2010). If this is the case, one arguably has to recognize in evaluation procedures that research, in order to achieve social impact, has to cross both disciplinary boundaries and those of other professional expertise and of social domains. Therefore, involvement of these domains and their stakeholders in evaluation design and practice is near to a necessity for assessing and achieving social impact.

In short, there is broad consensus about the importance of interactions between engaged parties from science and society. And in some fields practices do exist that take into account the importance of stakeholders by including them in evaluation procedures. However, when it comes to assessing the social impact of research in the majority of fields, knowledge about this interaction process is scarce and it is certainly undervalued and underused. In this article, we aim to clarify this iterative process between research and social context and to extract some indicators of more robust forms of social impact assessment. This enlightenment might help those in the European Commission, national governments or elsewhere, who promote the importance of collaboration between science, society, industry, and government, to achieve common goals such as (social) innovation and solutions for grand societal challenges.

\section{'Productive interactions', social impact and contextual learning}

We were able to research the interaction process between researchers and stakeholders in an FP7 project called Social Impact Assessment Methods for research and funding instruments through the study of 'productive interactions' between science and society (SIAMPI). ${ }^{1}$ We studied processes in four different research areas (healthcare, information and communications technology [ICT], nanosciences, and social sciences and humanities) in four different countries (the Netherlands, UK, France and Spain).

In this project, we understand productive interactions as exchanges between researchers and stakeholders in which knowledge is produced and valued that is both scientifically robust and socially relevant. These exchanges are mediated through various 'tracks', for instance, a research publication, an exhibition, a design, people or financial support. The interaction is productive when it leads to efforts by stakeholders to somehow use or apply research results or practical information or experiences. Social impacts of knowledge are behavioural changes that happen because of this knowledge. These changes may regard human well-being ('quality of life') and/or the social relations between people or organizations.

We use the concept of 'stakeholder' in a broad sense, that is, all those involved in achieving social impact: researchers, industry, public organizations, the government, the general public. To be sure, this approach has some major conceptual implications. We see social impact as a consequence of a process in which knowledge and expertise circulates to achieve certain goals that are deemed relevant for the development of society. Social impact can thus have multiple meanings depending on different social contexts. There is not always a clear distinction between social impact and 'productive interactions' because the transition from interaction to impact is often gradual. And opinions about positive or negative implications of certain impacts will most likely vary among stakeholders.

The consequences of this approach may look complex at first sight: 
1. The object of evaluation shifts from a research entity towards the process of interaction.

2. The number of stakeholders grows.

3. Reviewers are facing a greater challenge: they have to discuss matters not only with peers, but with a larger group of stakeholders; and they cannot simply rely on quantitative measures because these are not available for social impact measurement.

But on second thoughts, there are practical solutions for most of these issues: for example, there are techniques to discuss complex questions with a variegated group of stakeholders, and because of new possibilities for internet searches, more robust quantitative measures can be developed for impact assessment. And finally, this approach towards how social impact emerges from an interaction process will arguably enable a more insightful impact assessment, and raise awareness by all stakeholders about how social impact is attained.

In the SIAMPI project, we began by developing a new kind of evaluation approach through distinguishing three kinds of 'productive interactions' to reveal what goes on between different stakeholders and what the potential for social impact could be. These three kinds of productive interactions tell us how researchers communicate with their environment:

- Direct interactions: 'personal' interactions involving direct contacts between humans, interactions that revolve around face-to-face encounters, or through phone, email or videoconferencing.

- Indirect interactions: contacts that are established through some kind of material 'carrier', for example, texts, or artefacts such as exhibitions, models or films.

- Financial interactions: when potential stakeholders engage in an economic exchange with researchers, for example, a research contract, a financial contribution, or a contribution 'in kind' to a research programme.

Practically speaking, for each of these types of interaction, quantitative indicators and qualitative data (e.g. narratives, case studies) can be collected that can be used in assessment procedures. Some data will be readily available, while other data will have to be gathered through research. Some will be public, others might be confidential. Some are unproblematic because they take the form of traditional research outputs, others might be more complex and lead to debate, for example, use of new media. This is all part of any regular evaluation practice and arguably can be solved by experts. To be sure, interactions may overlap, involve many actors and modes of contact and exchange; they may occur either simultaneously or longitudinally through time. And stakeholders may take on different roles. For instance, an academic can act as a researcher, a paid consultant, a 'talking head' in a TV show, a reviewer, etc. In our approach to assessment, with a focus on the process, we are able to distinguish these roles and the part they play in the production of knowledge and impact.

The reason why we introduce 'productive interactions' as a pre-condition for the social impact of research is simple: in order to have impact you've got to have contact - direct, indirect and/or financial. However, as we will show in the next section, we learned that this is not always the case as social impact may result from chance (in the BRASS case) or unexpected consequences (in the NIVEL case). Overall we presume that interactions between researchers and stakeholders are near vital to achieve social impact.

This idea of the important role stakeholders play is not new (Freeman, 1974) and connects to ideas of national innovation systems in which science, government, industry and non-profit organizations interrelate in the context of socio-economic development (Godin, 2009). Social impact can be seen as the result of an intricate and iterative process between these four societal actors. Sometimes, it regards a concrete and measurable effect (e.g. a new medical technique), other times, it is about grander societal challenges that develop over time: a healthier lifestyle, cleaner cities, more user-friendly information systems, less $\mathrm{CO}_{2}$ emission.

The ways in which such impacts occur are often complex as they are the outcome of a dynamic process of actions and interactions between different stakeholders, in which scientific research is only one of the contributions. Social impact is difficult to plan; it sometimes happens unexpectedly, or can even be unintended. It is only by analysing the processes that induce impact that we have a chance of recognizing potential research impacts and the contributions made by research that might otherwise not be evident.

Focussing on 'productive interactions' will help to circumnavigate some of the problems described above. The existing lack of ready-to-use datasets might be reduced by developing indicators in the three sets of 'productive interactions' that identify important elements in creating (or obstructing) social impact. The variety of stakeholders and audiences in the different case studies, and the ways in which they communicate, and about what, will further shed light on how social impact can best be achieved. It also exposes differences in interest and

\section{It is only by analysing the processes that induce social impact that we have a chance of recognizing potential research impacts and the contributions made by research that might otherwise not be evident}


expectations between the different stakeholders. But in the end, this exposure might prove to be more 'productive' than ignoring these differences. The issues of attribution and temporality remain difficult. However, we will argue that the focus on 'productive interactions' allows us to distinguish the variegated contributions of researchers and stakeholders that taken together can be seen as necessary interim steps in the process that leads to social impact.

In the next section, we will highlight two of the main characteristic differences in contextualization that we encountered in the case studies, to illustrate the importance of knowledge about the specificities of the interaction process for the assessment of social impact. The first is how interaction is organized in different cases; the second is how researchers and stakeholders contribute to social impact.

Nowotny et al see a relationship between strongly contextualized knowledge production and socially robust knowledge: reliable scientific knowledge that is validated by relevant stakeholders (Nowotny et al, 2001: chapters 9 and 11). ${ }^{2}$ By 'strong contextualization' Nowotny et al denote a field where researchers have the opportunity and are willing to respond to signals received from society. The authors argue that the more contextualized knowledge production is, the more likely it is to produce socially robust knowledge.

Note that they picture the transformation of society as a co-evolution between science and society which highly interact in a 'transgressive arena'. Seen from a distance, and especially over a very long time, one will probably see such co-evolution in all fields of science. But a closer look, and during a shorter timeframe, will reveal differences per area. It is because of these expected differences that we find it necessary to explore different fields of research in our case studies.

\section{'Productive interactions': organization and contribution $^{3}$}

In four different research fields (healthcare, ICT, nanosciences, and social sciences and humanities) we sought to analyse and understand 'productive interactions' between researchers and stakeholders. We sought to find out in detail if and how these interactions can be introduced in assessment procedures for social impact. The case studies do not serve as 'ideal types' for the fields covered, but rather as illustrations of the various dilemmas and features of social impact assessment. Of the four cases only healthcare research can be seen as a more or less coherent field of research; the other three are best characterized as container concepts.

\section{Organization of 'productive interactions': coordination and serendipity}

Our case studies found different modes of organizing and maintaining 'productive interactions'. These ranged from highly coordinated interactions (top-down) with carefully chosen stakeholders, to chance interactions and serendipity (bottom-up). Explanations for these differences can be found in the different missions of research organizations and contextual variations; and to a lesser extent field differences play a role.

One example of high coordination is the Netherlands Institute for Health Services Research (NIVEL), ${ }^{4}$ a Dutch institute for healthcare and healthcare policy research. Here we found that, in order to fulfil its mission, NIVEL maintains interactions with a great variety of stakeholders, such as the Ministry of Health, other government bodies, professional groups, healthcare organizations, patient and consumer groups, healthcare insurers, and the general public. These interactions are organized by the board of NIVEL. It does so in order to safeguard financial support, and to enhance the chance of implementation of research results - and thus enhance potential social impact.

Not all participants in the consultation process are (potential) funders or collaborators. Some are found for other reasons to be important in enhancing the chance of success in implementation, or because of a specific expertise. Achieved social impact in this case is a result of a strategically organized iterative process with input from both researchers and stakeholders. ${ }^{5}$ It can be as diverse as a new medical guideline, improved diagnostics, a license or a new public-private partnership. The consultation process may include discussion of research results with stakeholders before publication in scientific or professional journals, which can be seen as a form of developing socially robust knowledge (Nowotny et al, 2001).

The external consultation process is complemented by a more informal interaction with stakeholders at the project level, which is more commonly found in academia. But in NIVEL these two levels of interaction are connected in specific internal meetings, thus ensuring a link between strategic goals and practical implications. This highly organized way in which NIVEL organizes its interaction both internally and externally reflects its mission as an applied and policy-oriented research institute whose main goal is to have a social impact in a relevant environment. It is relatively easy for a case like NIVEL to monitor and collect (quantitative) data about this interaction process (see also discussion section at the end of this paper). ${ }^{6}$

Quite the opposite was the case of the Centre for Business Relationships, Accountability, Sustainability and Society (BRASS), ${ }^{7}$ located at the University of Cardiff in Wales. BRASS also conducts research that is applied and policy-oriented in nature, revolving around social problems. But unlike NIVEL, there is no strong management policy to organize interaction between researchers and stakeholders. In the projects we have studied, we found numerous examples of a far more serendipitous pattern. 
A research project about social conflict in an Argentinean mining community is illustrative. The lead researcher previously carried out a study for the Welsh Assembly to develop a sustainability model; it was during a presentation of this model in a conference that a chance encounter took place with the professor who eventually became the main stakeholder in the mining project. The first interaction to have started this project was serendipitous in the sense that the connection between the researcher and stakeholder and the researcher was family-based: the researcher's brother was the professor's ex-doctoral student. Through the brother, the professor came to know the researcher's work in more detail and developed an interest in his model and BRASS research on extractive industries and corporate social responsibility.

Eventually the professor, through the University of Buenos Aires, funded the BRASS project on Social Conflicts in Mining in Argentina (20072009), and became its main stakeholder. She is not only a leading geologist, but also well-known by Argentine policy-makers, the mining industry and activist groups (NGOs) against mining. Though not a social scientist herself, she was interested in the application of social science techniques to the resolution of mining conflicts in Argentina, with which she was familiar. Her multiple roles in this project - she is both a stakeholder (for her involvement and interests in the politics of mining in Argentina), and a client (as a representative of the organization funding the research), as well as a researcher (as she collaborated with the Cardiff-based team) - show the importance of personal interest and motivation as well as serendipity in the interaction process.

So there are different ways of organizing and maintaining 'productive interactions' that can lead to social impact. When designing impact assessment procedures, one needs to be aware of these differences and take them into account. So for instance, while it would be possible to produce quantitative data concerning 'productive interactions' in the NIVEL case study, qualitative approaches are more appropriate to the BRASS case study because of the serendipitous pattern by which the 'productive interactions' occurred.

\section{Contribution instead of attribution}

A basic question for social impact assessment has always been to what extent one can attribute a social impact to specific research. By focussing on 'productive interactions', we shift the focus from attribution and impact to the contribution of specific actors, productive interactions and the exchange of knowledge and expertise by the various stakeholders. That way, we remain close to the process of knowledge production and the necessary communication between researchers and stakeholders. The case of a spin-off company in ICT and the search for evidence of social impact in nanoscience illustrates how.
In 1997, a researcher of the ICT department of the Free University in Amsterdam took part-time leave from his university job in order to develop a spin-off company in the field of semantic technologies. He was involved in the early stages of semantic web developments in Europe and he was motivated to make a connection between academic knowledge and the market. After working in the spin-off company for two years, when it became clear what the possibilities were to develop databases for the semantic web, the researcher returned to university. It still took a number of years, of extra investments, and of people working in the company, to develop a database that now serves as a building block of the semantic web. One of the tools developed by the company is now used by forensic and legal teams to investigate emails and computer files in order to discover and sort relevant evidence in fraud cases. There are multiple social impacts, and the tool generates income for the company.

While in 1997 social impact could only be seen in terms of its promise, and de facto social impact emerged more than a decade later, it would have been possible to assess this potential ex ante in 1997 if the productive interaction approach had been allowed in the evaluation. By assessing the contribution made to the process of innovation, in this case the step outside the university, we recognize the complexity of the route to achieving social impact and value some of the necessary steps in that process.

To complement this older case, we found that promise and expectations of potential social impacts abound in the relatively new field of nanosciences. Therefore, we expected to find emerging stakeholder contacts and 'productive interactions' gearing up for an array of specific social impacts. However, this was rarely the case. An important reason for this appeared to be the long temporality between basic research and social impacts in terms of end-user products, arguably the longest time-lag of all our case studies. A more detailed analysis is necessary to find and understand the productive interactions. The researchers we interviewed, both in the Netherlands and France, largely indicated that they do fundamental research, remote from any specific application.

Looking more closely at the field in terms of a network, we see a rather intricate pattern of basic academic research groups, non-academic research institutes, spin-off companies, commercial companies, professional end-users and consumers. Academic researchers work much more closely together with other research groups and in some cases with other research institutes outside academia, than with all the other participants in the network. For example, to test or show a certain phenomenon, they build prototypes or demonstrators (an indirect interaction) that are sometimes tested by other research groups. These other groups give feedback to the original researchers and provide input concerning performance expectations or standards in particular fields or 
applications. They act as intermediary between two parts of the development to social impact. This helps the researcher to improve the prototype, and this might provide clues for commercialization. Elsewhere in the network, spin-off companies can be found that 'translate' and further develop results from the testing phase to industry or professional users. And in yet another place, companies are funding application-driven $\mathrm{PhD}$ projects. All these phenomena may serve as examples of 'productive interactions' and of the variation in contributions to an eventual social impact.

By using 'productive interactions' it is possible to identify the contributions of the researchers to potential social impact further on. Also, by staying close to the activities of researchers, we noticed the 'enlightenment' function of 'productive interactions': both researchers and management began to understand that social impact is not only a faraway goal, but can be seen as a process in which each step is valuable, the beginning (a contact, an article, a public debate), the middle (a joint venture, a prototype, a new protocol or rule), and the end (a product, a service, a new organization).

\section{Discussion}

The 'productive interactions' approach aims at narrowing the gap between developments in the theory of creating social impact and the evaluation practice in social impact assessment by focussing on 'productive interactions' throughout the research process and on the societal context in which these occur. While in some sectors a practice has developed of interactive evaluation in which stakeholders play a vital role, such as in education and development interventions, the practice of research evaluation in most sectors is still dominated by peer review. While in theory most analyses take on an interactive perspective when it comes to social impact of research, the practice of research evaluation is still dominated by linear models. By maintaining a basically linear perspective, common difficulties with the assessment of social impact are hard to solve, such as the long time-lag between research, application, and social impact, and the problem of attributing a particular impact to a specific research endeavour.

Instead, in this paper we propose to understand social impact in a broader context, yet close to the activities of researchers and stakeholders. We focus on the small but necessary steps in the process of achieving social impact. These steps materialize in three types of 'productive interactions' and can be seen as intermediate indications of de facto social impact. These indications refer to contributions and uptake by researchers and stakeholders and serve as an early 'warning' system for social impact. In short, the approach to the assessment of social impact presented in this paper differs from most methods currently used in the following ways.
It is process-oriented, valuing the small but necessary steps in an intricate course of interactions

We propose a shift from a focus on social impact towards a focus on 'productive interactions'. This way, a much more realistic approach is offered, that is closer to the actual process that the researcher is able to influence, that is closer to the actual practice of the researcher doing research and interacting with stakeholders. De facto social impact in the sense of an objective and measurable effect is not neglected, but since those effects only develop over a long time, it is not our prime focus.

\section{It is contextual, and so takes into account the vital role of the contributions of researchers and stakeholders alike}

This offers a solution to the time-lag and attribution problems. Instead, our approach focuses on the small steps of all involved in this complex process. Several contributions and uptakes will usually be necessary in order to reach impact, some simultaneously, some chronologically, and of different kinds, e.g., financial, commercial, political, environmental, societal and or scientific.

The approach also has consequences for the definition of stakeholders. Initially, as is common in most other approaches, we excluded (academic) researchers from our definition of stakeholders. However, by focussing on the process, and on the contributions and uptake by various participants, academics in neighbouring fields become stakeholders as well. Also, the focus on 'productive interactions' might reveal intermediate impacts along the way, such as ICT researchers developing solutions for researchers in other fields, including medicine and biology (De Jong et al, forthcoming).

\section{It is oriented towards learning and improving rather than judging and accounting}

Whereas evaluations are often used for accounting purposes, we propose to use evaluation as a learning tool that helps us understand what goes on between researchers and stakeholders. Assessments can then result in recommendations for improvement in the interaction necessary for achieving social impact. Being a learning tool also means that the knowledge and perspectives of all involved researchers and stakeholders are somehow included in the evaluation process.

\section{Indicators}

The contributions to achieving social impact of all involved can be identified with the help of indicators in each of the three productive interaction categories. These indicators might result in a more realistic description that goes beyond the common paragraph filled with futuristic expectations in the long term. 
While there is never a shortage of indicators, there is often a lack of robust data. Besides, the indicator alone does not tell the full story; the indicator serves to illustrate the narrative. Having said that, we now give some examples of indicators that we used in the cases.

In the first category of direct, personal interactions, indicators often are of a qualitative nature. In our case studies we found the following interactions that may serve as a basis for indicator development: face to face communications with user communities, with clinical and charity professionals, with peer groups, with administrators, and with commercial companies. While it may not make much sense to quantify these different personal interactions, let alone to weigh them, taken together they present a good picture of the activities of a group of researchers vis-à-vis stakeholders. Some examples of quantitative indicators are the number of researchers holding dual posts, the number of memberships of advisory committees and the number of presentations for lay audiences. Again, it does not make sense to weigh them, but they present a picture of the researcher or group vis-à-vis stakeholders.

In the second category, we tested a quantitative indicator called contextual response analysis (CRA), developed by one of our team members, Ad Prins. Through CRA we can identify the contextual interest (or uptake or use) concerning reports, papers and other output. In the NIVEL case, this showed a wide variety of interested stakeholders in various social domains, as shown in Figure 1. Through internet searches of key words in the title of the NIVEL outputs, we found interest in five different social spheres: science, communication, government, the health sector, and a general category.

In the third category of productive interactions, financial interactions, quantitative indicators are by nature more easy to find. This includes, for example, contracts, licenses, project grants, sharing of facilities, personal sponsorships, travel vouchers. PhD funding by industry is a very common indicator, as a rule tied to some form of (expected) application.

\section{Additional value}

Our case studies have shown that social impact can become a more tangible concept for researchers and management. By discussing social impact in terms of the three kinds of 'productive interactions', it became clear that data could be gathered that can give useful information about steps that are necessary to achieve social impact and about the relationship with various stakeholders. Also, the researchers became more aware of the value of their contributions to social impact. Some of them didn't know how to handle the issue of social impact before, or thought their work didn't have any (evidence of) social impact. By discussing the issue with them further, they realized what could be included in social impact, or what their contribution to a (potential) impact was or might be. Our case studies and interviews acted thus as an 'enlightenment tool' that allowed participants to understand what social impact was and what their role is in achieving impact. Given that the academic community is struggling with the concept of social impact, researchers and funding agencies can benefit from such 'enlightenment' tools.

Finally, the enlightenment function also works for stakeholders. In one particular case the stakeholder, a theatre director, wasn't aware how much the work of the academic group he collaborated with had influenced his performance. It only became apparent to him during the interview that he had changed the performance drastically, primarily based on his collaboration with an academic group.

\section{Drawbacks}

A number of pitfalls have been identified. One is that 'productive interactions' runs the risk of becoming a 'container concept', including stakeholder

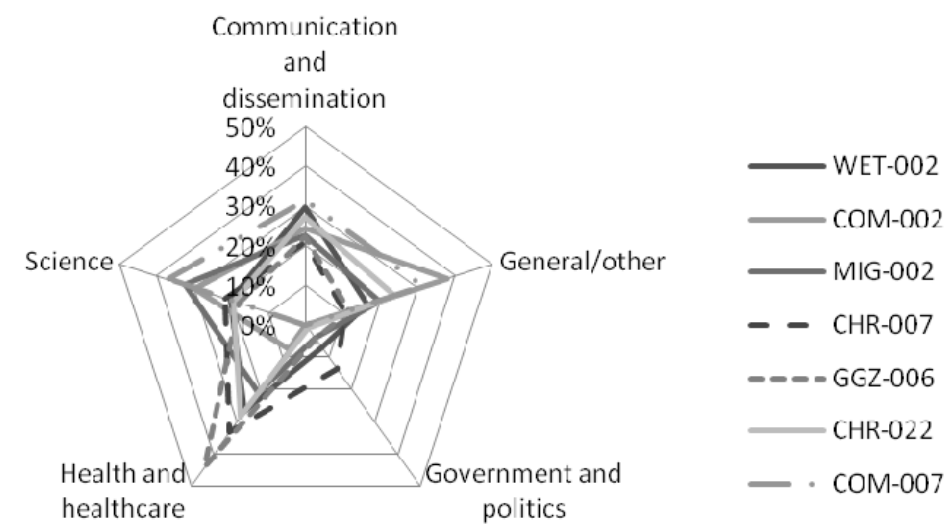

Figure 1. Contextual interest in NIVEL

Note: The column on the right refers to seven large research projects of NIVEL. Percentages refer to the share of total output of research projects (publications, press releases, other online material) as viewed via the internet by audiences in a particular social domain. Google and Yahoo search engines were used to track down the output 
workshops, websites for the general public and acquisition of funds. However, it is not the productive interaction per se that is important, but the role it plays in the process of realizing social impact. This goes beyond ticking boxes or mentioning types of 'productive interactions'. It includes the narrative: the aim of the interactions, the context of research, and the stakeholders involved.

Another pitfall is that this approach might entail conflicting narratives. Stakeholders and researchers might come up with different and competing views. In the case of evaluation for accounting purposes, this is leads to a problem: who to believe? In the case of the approach presented in this paper, chances are that such a conflict might be resolved, either by evidence from data about the 'productive interactions', or because of the willingness of the participants to resolve the differences, since the focus is on learning and not on accounting.

In the SIAMPI project we have studied a variety of research fields and organizational contexts in a number of national settings. Our purpose was not to compare, but to gain insight into the relation between 'productive interactions' and social impact. We are confident that the approach is useful in a wide variety of evaluation situations. This goes for types and modes of research, for regional, national and international contexts and for ex ante and ex post evaluations. The main reason is that our approach is contextual and focuses on the activities of both researchers and stakeholders, it stays close to the daily activities of both researchers and stakeholders. Some of the case-study organizations have indicated that the approach is or will be used for evaluations: both Dutch organizations in the healthcare study, and the Spanish organization involved in the social sciences and humanities case study.

Finally, we do not propose a ready-for-use-tool, but a framework for assessment that can be modified for each situation. This is due to the contextdependent nature of 'productive interactions' in creating social impacts. But the framework offers a clear road to an assessment procedure. First of all there are the three types of 'productive interactions' (direct interactions, indirect interactions, and financial interactions). For each of these it is possible to gather data about field-specific indicators that give information about contribution and uptake. Second, it involves all stakeholders in the assessment procedure, either by making (some of) them part of the review committee, or by giving them another position, for example in a focus group. And third, through making improvement a central objective and not accounting, it ensures that learning is part and parcel of the procedure.

\section{Notes}

1. The Royal Netherlands Academy of Arts and Sciences (KNAW) coordinated this project. Partners were from the
Netherlands (Rathenau Institute), France (CNRS-MSH), England (University of Manchester) and Spain (University of Valencia - CSIC). SIAMPI ended in February 2011.

2. Alternative approaches to strong contextualization that stress the 'strength of weak ties' can be found in Nooteboom (2006).

3. This section of the paper draws on the case studies conducted by Ad Prins (healthcare), Puay Tang, Elena Castro-Martinez and Jordi Molas-Gallart (social sciences and humanities), Stefan de Jong, Peter van den Besselaar, Kate Barker, Deborah Cox, Kathryn Morrison, Thordis Sveinsdottir, Diana Pearson and Beatrice D'Oppolitto (ICT) and Tilo Propp, Barend van der Meulen, Anne Marcovich and Terry Shinn (nanosciences).

4. About a third of NIVEL's funding comes from the Dutch Ministry of Health, in a yearly lump sum on the basis of a negotiated agenda for research priorities. The remaining two-thirds of the funding comes from grants (research councils, charity funds, the European Commission).

5. Note there is no 'level playing field' for all stakeholders. Following the typology of Mitchell et al (1997), we found dominant (government with specific demands or expectations), discretionary (funders that rely on peer/expert review) and dependent stakeholders. Dependent stakeholders have fewer intellectual and financial resources than the other two.

6. In this particular case study we experimented with a quantitative method to measure the impact of professional and popular publications of NIVEL: Contextual Response Analysis developed by Ad Prins, <http://www.adprins.nl/index.php?id= werkwijze>, last accessed 7 July 2010.

7. BRASS is an interdisciplinary research centre, funded by the UK Economic and Social Research Council.

8. Because we are discussing social impact assessment we exclude indicators that are used for assessing the academic 'impact' of research within the scientific community, as referred to in the first paragraph of this paper.

\section{References}

Cozzens, S and M Snoek 2010. Knowledge to policy: contributing to the measurement of social, health, and environmental benefits. Paper prepared for Workshop on the Science of Science Measurement, Washington, DC, 2-3 December 2010.

De Jong, Stefan P L, Kate Barker, Deborah Cox and Peter van den Besselaar forthcoming. Societal impact of enabling research fields: ICT research: a Dutch and a UK case.

European Commission 2005. Assessing the Social and Environmental Impacts of European Research. Luxembourg: European Commission.

Freeman, C 1974. The Economics of Industrial Innovation. Harmondsworth: Penguin Books.

Godin, B 2009. National Innovation System: the system approach in historical perspective. Science, Technology and Human Values, 34(4), 476-501.

Guba, E G and Y S Lincoln 1989. Fourth Generation Evaluation. Newbury Park, CA: Sage.

Mitchell, R K, B R Agle and D J Wood 1997. Toward a theory of stakeholder identification and salience: defining the principle of who or what really counts. Academy of Management Review, 22(4), 853-886.

Nooteboom, B 2006. Cognitive distance in and between COP's and firms: where do exploitation and exploration take place, and how are they connected? Paper for DIME Workshop on Communities of Practice, Durham, 27-28 October 2006.

Nowotny, H, P Scott and M Gibbons 2001. Re-thinking Science: Knowledge and the Public in an Age of Uncertainty. Cambridge: Polity Press.

Smits, R and S Kuhlmann 2004. The rise of systemic instruments in innovation policy. International Journal of Foresight and innovation Policy, 1(1/2), 4-32.

Spaapen, Jack, Huub Dijstelbloem and Frank Wamelink 2007. Evaluating Research in Context: a Method for Comprehensive Assessment. The Hague: COS

Vaessen, Jos 2010. Challenges in impact evaluation of development interventions: opportunities and limitations for randomized experiments. IOB Discussion paper 2010-01, University of Antwerp.

Volberda, Henk et al 2010. Sociale innovatie: nu nog beter! Erasmus Concurrentie en Innovatie Monitor 2009-2010. Rotterdam: INSCOPE. 